\title{
Estratégias reprodutivas de agricultores familiares em Botuverá, Santa Catarina, Brasil ${ }^{*}$
}

\author{
Cíntia Uller-Gómez ${ }^{1}$ \\ Maria José Reis ${ }^{2}$ \\ Universidade do Vale do Itajaí \\ Luiz Fernando Scheibe \\ Universidade Federal de Santa Catarina
}

Este trabalho tem como objetivo discutir as estratégias reprodutivas presentes entre agricultores familiares de Botuverá/SC. Encontramos que o processo decisório sobre o uso da terra é fortemente atrelado à indissociabilidade das categorias camponesas "terra", "trabalho" e "família" e a categorias específicas dos colonos do sul do Brasil, tais como "liberdade", "capricho com a terra" e "trabalho árduo". Destacamos ainda a importância da produção para consumo familiar e o recurso a atividades não-agrícolas como estratégias de reprodução da unidade produtiva e a fumicultura como uma atividade que ameaça essa reprodução.

Palavras-chaves: Agricultura familiar - Produção para consumo familiar - pluriatividade - fumicultura; colonos.

The purpose of this article is to discuss the reproductive strategies of family farmers in Botuverá, SC. We found that decision making about the use of land among the families interviewed is strongly tied to the inseparability of the peasant categories "land", "labor" and "family" and the specific categories of the colonos of southern Brazil, such as "freedom", "care for the land" and "hard work". We also highlight the importance of production for the farm families own consumption, their turning to non-agricultural activities as strategies for reproduction of the productive unit and tobacco raising as an activity that threatens this reproduction.

Keywords: Family farming - Production for family-consumption - Pluriactivity - Tobacco farming - Colonos.

\section{Introdução}

uitas das instituições que se dedicam à recuperação ambiental de bacias hidrográficas têm como foco os estabelecimentos rurais, que são, muitas vezes, os locais onde se encontram as nascentes dos cursos d'água.

\footnotetext{
* Reproductive strategies of family farmers in Botuverá, Santa Catarina, Brazil

${ }^{1}$ Engenheira agrônoma, doutora em Ciências Humanas pelo Programa de Pós-Graduação Interdisciplinar em Ciências Humanas/UFSC. (cintiaug@yahoo.com.br).

2 Professora aposentada e colaboradora do Programa de Pós-Graduação em Antropologia Social da UFSC e professora titular da UNIVALI. (masereis@hotmail.com).

${ }^{3}$ Professor titular da UFSC, orientador no Programa de Pós-Graduação em Ciências Humanas e no Programa de Pós-Graduação em Geografia da UFSC. Endereço para correspondências: UFSC/CFH/ GCN, Campus Universitário, Trindade, Florianópolis, SC, 88040-900 (scheibe2@gmail.com)
} 
Da visão que tenham os gestores públicos a respeito dos agricultores que vivem nesse espaço, vai depender grande parte da qualidade de ações a serem tomadas em seu respeito.

Este trabalho tem como objetivo discutir as estratégias reprodutivas presentes entre agricultores do município de Botuverá/SC, na Bacia do Rio Itajaí (Santa Catarina, Brasil), em sua maioria, caracterizados pelo pequeno tamanho de seus estabelecimentos produtivos, pela ascendência européia, pelo uso quase exclusivo da mão-de-obra familiar e pelo recurso frequente a fontes de renda não-agrícolas. Estas características são comuns a toda a Bacia do Itajaí, que abrange total ou parcialmente cinqüenta municípios ${ }^{4}$. Por conta disso, um estudo deste tipo pode trazer luz às estratégias de conservação ambiental naquela bacia de modo que se respeite a diversidade sócio-cultural existente em seu espaço rural.

O município de Botuverá faz divisa com os municípios de Guabiruba, Blumenau e Indaial ao norte, Nova Trento ao sul, Vidal Ramos e Presidente Nereu a oeste e Brusque a leste e, segundo o IBGE (2004a), possui uma área de $317,24 \mathrm{~km}^{2}$. À área urbana correspondem apenas $2 \mathrm{~km}^{2}$, e os demais 315,24 $\mathrm{km}^{2}$ são considerados área rural.

A partir do final do século XIX, Botuverá passou por um processo de colonização com imigrantes europeus (não ibéricos), sobretudo, italianos. Os próprios sobrenomes dos agricultores verificados em formulários existentes na Unidade de Saúde confirmam que a grande maioria dos agricultores de Botuverá descende destes imigrantes.

De acordo com Eckert (1985), até 1946, a agricultura em Botuverá era destinada principalmente ao consumo da família. A partir dessa data, através da integração com as indústrias fabricantes de cigarros, se deu início ao plantio de fumo em folha nas pequenas propriedades rurais. Segundo o mesmo autor, a partir de 1954, a cultura do fumo começou como "fenômeno generalizado", havendo outra "onda forte" em 1964.

Tamanha é a diferença verificada na vida dos agricultores a partir do plantio do fumo em suas propriedades que Eckert (1985) divide a história do município de Botuverá em antes e depois do fenômeno da fumicultura. Como afirma esse autor (e como nós mesmos pudemos ouvir dos próprios agricultores) foi por meio do cultivo do fumo que muitas famílias puderam ter acesso a condições mínimas de conforto em suas residências.

\footnotetext{
${ }^{4}$ Agrolândia, Agronômica, Alfredo Wagner, Apiúna, Ascurra, Atalanta, Aurora, Benedito Novo, Blumenau, Botuverá, Braço do Trombudo, Brusque, Chapadão do Lageado, Dona Emma, Doutor Pedrinho, Gaspar, Guabiruba, Ibirama, Ilhota, Imbuia, Indaial, Itaiópolis, Itajaí, Ituporanga, José Boiteux, Laurentino, Lontras, Luiz Alves, Mirim Doce, Navegantes, Penha, Petrolândia, Piçarras, Pomerode, Pouso Redondo, Presidente Getúlio, Presidente Nereu, Rio do Campo, Rio do Oeste, Rio dos Cedros, Rio do Sul, Rodeio, Salete, Santa Terezinha, Taió, Timbó, Trombudo Central, Vidal Ramos, Vitor Meireles e Witmarsum.
} 
De acordo com o Censo Agropecuário 1995-1996 os estabelecimentos agropecuários de Botuverá são em número de 268 (IBGE, 2004b), nos quais estão ocupadas 1.054 pessoas (de 14 anos ou mais). Em aproximadamente $85 \%$ destes estabelecimentos, a mão-de-obra é constituída apenas pelos responsáveis pelo estabelecimento e seus familiares, nos quais estão ocupadas 871 pessoas (de 14 anos ou mais de idade).

Até os dias atuais, a produção agrícola do município continua centrada na cultura do fumo. Conforme indicam os dados do IBGE (2004c), essa cultura ocupava, em 2002, aproximadamente 332 ha, representando $70 \%$ da área de lavouras temporárias do município. As lavouras permanentes são inexpressivas - para o ano de 2002, o IBGE (2004d) apresentava apenas 7 ha destinados à cultura do pêssego.

Conhecidos esses dados, as estratégias metodológicas da pesquisa consistiram, sobretudo, de observação direta nos estabelecimentos rurais e da realização de 32 entrevistas semi-estruturadas com agricultores que foram selecionados após consulta a informantes-chaves e aos dados disponíveis na Unidade de Saúde Municipal, de modo a abranger a diversidade sócio-cultural existente.

Para análise das estratégias reprodutivas desses agricultores, entre outros autores, nos reportamos, sobretudo, aos valores próprios ao campesinato referenciados por Woortmann (1990), a partir dos quais a terra não é pensada isoladamente do trabalho e da família; mais do que meio de produção, a terra é concebida como patrimônio da família. Além disso, fez-se necessário levar em conta os valores que são especialmente prezados pelos agricultores familiares conhecidos pelo termo "colono".

De acordo com Seyferth (1993), o termo "colono" foi atribuído aos imigrantes pelas leis e regulamentos que nortearam a política de imigração no século XIX e, desde então, passou a ser assumido pelos indivíduos que eram por ele classificados como uma identidade social ligada à imigração. Seyferth (1993: p.98) afirma que a categoria "colono" expressa uma identidade social que tem duplo significado: indica, em algum grau, uma condição camponesa; ao mesmo tempo possui um conteúdo étnico irredutível vinculado à "origem" (européia), a partir do qual a capacidade de trabalho e o amor à terra são tidos como inatos. Seyferth (op.cit.) menciona como elementos de categorização: o trabalho familiar, a posse da terra em quantidade suficiente para permitir o cultivo, a produção voltada em primeiro lugar para o consumo doméstico (privilegiando-se assim a policultura com criação de animais), a participação nas atividades comunitárias, a dedicação à terra, o trabalho árduo, o enraizamento, a liberdade como valor e a propriedade da terra.

Relacionado aos "colonos", o termo "colônia" é essencial para compreendermos o significado das práticas dos agricultores: conforme Seyferth (1985: p.8), "numa oposição entre cidade e campo, o termo "colônia" designa a área rural; 
mas a nível de comunidade rural também tem um significado mais estrito e, diria, mais sociológico. Designa as terras, benfeitorias, residências, animais domésticos, plantações, etc., que juntamente com o grupo doméstico, formam uma unidade básica de produção e consumo. A concepção da família camponesa está estreitamente ligada à idéia de colônia [...]. Constitui a própria caracterização desse campesinato, onde o trabalho familiar, tanto quanto a propriedade da terra, são extremamente valorizados. A Colônia nesse contexto, é tanto a terra quanto o produto do trabalho e do esforço da família".

Analisando os dados disponíveis na Unidade de Saúde Municipal, encontramos um grande número de famílias em que um ou mais membros exerciam também atividades não-agrícolas. Este fato caracteriza o que diferentes autores têm denominado de "pluriatividade", no seguinte sentido, expresso Schneider (2003a: p.112): "um fenômeno através do qual membros das famílias que habitam no meio rural optam pelo exercício de diferentes atividades, ou, mais rigorosamente, pelo exercício de atividades não-agrícolas, mantendo a moradia no campo e uma ligação, inclusive produtiva, com a agricultura e a vida no espaço rural". De acordo com este sentido, os indivíduos ou as famílias que exercem atividades agrícolas e não-agrícolas são chamados "pluriativos(as)".

As atividades agrícolas e não-agrícolas fazem parte do processo de reprodução social que Fortes (1958) apud Almeida (1986: p.67) define como "o processo de manter, repor e transmitir o capital social de geração em geração, sendo o grupo doméstico seu mecanismo central, o qual tem simultaneamente uma dinâmica interna e um movimento governado por suas relações com o campo externo". De acordo com Almeida (1986: p.67-68), a reprodução social dos grupos familiares se dá em dois ciclos complementares: ciclo anual ou curto - no qual combina-se trabalho, recursos naturais e conhecimentos tradicionais para atender o consumo familiar e para repor os insumos necessários ao reinício do processo - e o ciclo geracional ou ciclo longo - no qual as famílias se perpetuam através das gerações, e é nele que ocorre a migração, o controle sobre o patrimônio, a herança, o corporativismo de parentes e emergem formas diversas de famílias.

\section{O perfil sócio-econômico e a reprodução social das famílias entrevistadas}

Das 32 famílias entrevistadas, 10 (dez) exerciam apenas atividades agrícolas; em 11 (onze) a atividade agrícola era praticada apenas pelos pais enquanto os filhos exerciam atividades não-agrícolas; em 14 (catorze) famílias tanto a atividade agrícola como a não-agrícolas estavam distribuídas entre os diversos membros da família num complexo arranjo familiar e em 4 (quatro) famílias em que a agricultura tinha pouca expressão sendo destinada apenas ao consumo familiar. 
De uma maneira geral, verificamos que o uso da terra é decidido segundo as condições micro-climáticas do terreno conhecidas pelo agricultor, as condições de mercado, as possibilidades da comunidade local em suprir principalmente alguma demanda de mão-de-obra temporária, bem como a mãode-obra disponível na família e os desejo dela. Freqüentemente os agricultores se referiram às dificuldades de colocação de seus produtos no mercado com preço que possibilitasse algum retorno econômico da atividade. Para tanto, articulavam seu discurso em torno de fatores econômicos que escapam ao seu controle, como a decisão do preço de produtos como milho e feijão. Essa dificuldade econômica contribuía na decisão de destinar mais ou menos a área a esses tipos de cultivo. Por outro lado, esses tipos de cultivos, mesmo sem retorno econômico, estavam sempre presentes nos estabelecimentos rurais. Eles são essenciais "para o gasto da casa". Esta expressão é usada com freqüência pelos agricultores como referência aos produtos destinados ao consumo interno ao estabelecimento rural, seja diretamente na alimentação humana, seja para alimentação das "criações" - dos animais domésticos destinados ao consumo ou ao mercado, em pequenas quantidades. Invariavelmente, eram cultivados "para o gasto": milho, feijão, batata-doce, mandioca, verduras de vários tipos e frutas. Com menor freqüência foram mencionados pelos agricultores, abóbora, mangarito, amendoim, café, cará, cebola e alho. Quanto aos animais domésticos, estavam sempre presentes porcos, galinhas, gado bovino para corte e pelo menos uma vaca de leite. Com menor freqüência ovinos, patos e peixes.

Em resumo, nas decisões tomadas sobressai-se a centralidade da família, seja em termos de mão-de-obra disponível, seja em termos de seu projeto de vida, contando-se os desejos individuais de seus membros. As tomadas de decisão que levam em conta a "família" são feitas com base numa relação complexa entre pragmatismo e simbolismo, mais ou menos orientada por valores camponeses em geral, e do "colono" em particular.

Dentro da combinação entre as necessidades pragmáticas e o valor simbólico atribuído às diferentes práticas executadas pelos agricultores familiares entrevistados, sobressai-se a importância do cultivo do fumo que tem sido a única cultura comercial com destaque no município, desde a metade do século XX. A seguir discutiremos como os agricultores familiares elaboram diferentes arranjos familiares, sempre balizados pela importância dada aos valores camponeses, levando em conta as necessidades pragmáticas desse cultivo. A centralidade da família no que diz respeito à possibilidade de atender a essas necessidades pragmáticas ou aos desejos de seus membros, orienta as decisões para que se permaneça ou não plantando fumo. Dentre arranjos familiares está o recurso à pluriatividade, o que não diminui a importância da produção para consumo familiar - sempre ressaltada pelos agricultores. 


\section{2. $O$ cultivo do fumo}

À exceção de uma das famílias entrevistadas, a qual não é originária do município, todas têm a cultura do fumo em sua história. Assim, as decisões em torno dos três fatores mencionados acima, em algum momento da história do grupo familiar, tiveram como um dos critérios as condições necessárias à prática desse cultivo. Nas entrevistas realizadas ficou claro que o fumo é uma cultura agrícola que permite verificar, por excelência, como as necessidades pragmáticas, sobretudo de mão-de-obra, se articulam com as categorias simbólicas do discurso do "colono" - terra, trabalho, família, comida, liberdade e trabalho árduo - apontadas por Seyferth (1993).

A maioria dos agricultores entrevistados visualiza o fumo como a única cultura que encontra mercado garantido e, portanto, permanecer na roça é sinônimo de cultivar fumo - "Se sair do fumo, tem que sair daqui mesmo. Porque não tem outra coisa para fazer". Além disso, o fumo é percebido como um produto com garantia de compra pelas empresas fumageiras, enquanto que outras culturas "não se acha de vender".

Diante das exigências do cultivo do fumo, evidenciam-se as categorias identificadoras do colono. Em todos os estabelecimentos produtivos que visitamos em que se produzia fumo, o cultivo era feito com, no mínimo, duas pessoas da família. Na época da colheita em que é maior a demanda de mão-de-obra, quando não há mais mão-de-obra disponível na família, contrata-se uma pessoa temporariamente. Em muitos casos, aquele que é "pago por dia" é também um parente próximo. Ao mesmo tempo em que existe a demanda pragmática de mão-de-obra, o "valor família" conta nas decisões tomadas em torno do cultivo do fumo, seja para abandoná-lo, seja para continuá-lo.

Registramos um caso em que um agricultor que havia ido trabalhar na cidade retornou porque "em casa tinha pouca gente e quis ficar com o irmão". Sozinho, o irmão não poderia mais produzir na roça. O valor família e o princípio da reciprocidade pesaram na hora da decisão. Exemplificamos também com o caso de outra família que em que os pais, mesmo não precisando mais trabalhar com o fumo, o faziam para ajudar o filho que não se adaptava a empregos urbanos e não dispunha da mão-de-obra da esposa que cuidava do filho pequeno.

No entanto, em várias famílias, a reprodução da unidade produtiva não é visualizada com certeza pelo pai de família. Existem famílias em que os filhos já abandonaram a atividade agrícola e só os pais permaneceram na agricultura. Na maioria dessas famílias, assim como nos exemplos anteriores, os filhos começaram a exercer atividades não-agrícolas quando, na casa paterna, se cultivava fumo. 
Em outras famílias em que os filhos ainda não estavam em idade de escolher sua profissão, as atividades não-agrícolas foram procuradas porque o fumo já não dava o retorno econômico necessário ou ainda porque a família não dispunha da mão-de-obra necessária para o seu cultivo. Como o fumo é a única cultura agrícola capaz de gerar renda considerada "garantida", diante da impossibilidade de obtê-la, os próprios cônjuges procuram atividades não-agrícolas para garantir a renda familiar.

\section{Produção para consumo familiar, pluriatividade e reprodução social}

Considerando o conceito de reprodução social (FORTES, 1958 apud ALMEIDA, 1986) é indispensável afirmar que em todas as famílias em que um ou ambos os cônjuges praticavam atividades não-agrícolas, a produção para consumo familiar não foi abandonada e é muito valorizada. A produção do próprio alimento como categoria identificadora do colono permanece nessas famílias, mesmo que na maioria delas a continuidade da atividade agrícola pelos filhos não seja, no momento, visualizada com certeza pelos pais. Em geral, mesmo quando os dois cônjuges têm alguma atividade não-agrícola, em algum momento ambos se dedicam ao uso da terra, mesmo que seja nos fins de semana ou esporadicamente, quando não precisam se dedicar à atividade não-agrícola. Por outro lado, em apenas um caso verificamos que a produção agrícola destinava-se exclusivamente ao consumo familiar. Na grande maioria das vezes algum excedente era vendido. Em geral são produtos perecíveis que não podem ser armazenados por longo tempo, como queijo, leite e ovos. Também são comercializados: as galinhas que já não servem para postura, milho e batata-doce excedentes e até mesmo suco de frutas que são preparados e congelados para venda em casa. Outra prática bastante corrente entre os agricultores, mesmo entre os pluriativos, é a manutenção de uma pequena quantidade de matrizes de suínos com o objetivo de vender os leitões para outros agricultores, os quais farão a engorda dos animais para consumo próprio.

Eu classifico assim, o colono em dois tipos. Eu classifico: O colono, aquele que planta fumo e é colono e digo que existe o plantador de fumo. Que o cara que só planta fumo e ele não produz tudo o que puder pro alimento, consumo da casa, ele é simplesmente um plantador de fumo.[...] $O$ colono que não produz o suficiente para o consumo, ele não é colono. Pra mim, ele não é colono. Eu digo sempre pros meus filhos, hoje em dia, nós temos a fábrica de conservas, no lugar da nossa gente, a nossa família, ir trabalhar de em- 


\section{HUMANAS}

pregado. E hoje ela aumentou que entrou as três noras. Nós temos mais 4 empregados. Então, eu sempre digo para eles, se dá lucro ou prejuízo, não interessa. Agora o necessário para o gasto, esse fizemos, o mais que nós pudermos. Tem ano que não planta feijão, não planta batatinha, essas coisas pequeninhas [...] Mas o grosso, como o milho, isso, aquilo, a carne que é cara... Nós temos galinha, temos porcos, temos vaca de leite, temos tudo. (Agricultor pluriativo, 55 anos, Localidade Vargem Grande).

Em alguns casos, diante da impossibilidade de manter a propriedade produtiva se os dois cônjuges forem pluriativos, um deles permanece na propriedade. Quando os dois cônjuges exercem atividades não agrícolas, geralmente um deles (ou mesmo os dois) trabalham na própria residência ou um deles dispõe de horário de trabalho flexível. Uma das preocupações presentes também entre os pluriativos é a de "manter a terra limpa", o que significa manter a terra em condições de uso, sem que a mata nativa se regenere, de modo que, quando for necessário, ela esteja disponível para ser usada. Esta "necessidade", além do aspecto pragmático - a terra estará em condições de uso quando for necessitada - está ancorada na concepção de "capricho", de "cuidado" com a terra - registrada por Seyferth (1993) quando estudou os colonos do Vale do Itajaímirim (nos municípios de Brusque e Guabiruba), em que a presença de "capoeira nas roças" desqualificava o colono.

Assim, a procura de atividades não-agrícolas, não necessariamente representa a negação da tradição, da campesinidade. Os agricultores (já casados) pluriativos evocam categorias do camponês tradicional para justificar sua permanência na terra, especialmente a categoria "comida", informando, além do seu significado simbólico, a necessidade pragmática da segurança alimentar. Também enfatizaram a qualidade de vida do espaço rural em oposição ao espaço urbano, expressada pela liberdade de estar ao ar livre - "Aqui as crianças podem correr... Se for para sair daqui, a gente volta a plantar fumo".

Como no trabalho de Seyferth (1984), sobretudo quando são os cônjuges que recorrem a atividades não-agrícolas, esta vem para substituir a renda antes obtida com um produto agrícola destinado ao mercado - nas famílias por nós entrevistadas, o fumo. Por outro lado, não podemos afirmar que a unidade agrícola produtiva e que os valores camponeses serão repassados para a geração seguinte, porque em alguns casos em que os filhos já poderiam contribuir em alguma tarefa agrícola, não o faziam. A falta de terra também foi o motivo que levou alguns filhos adultos de casais pluriativos a procurarem também uma atividade não-agrícola - "Foram obrigados a trabalhar tudo fora porque não tem terra. 
Pouca terra". Mas estes filhos tampouco participavam das tarefas agrícolas na terra dos pais. O saber-fazer não estaria sendo transmitido e, parafraseando Woortmann (1990: p.43), "a transmissão da terra sem o saber não transformaria esta terra em terra de trabalho, nem em patrimônio familiar". No entanto, para esta geração adulta, a atividade não-agrícola realizada por membros da família rural não significava a proletarização, e os valores da identidade de colono são freqüentemente evocados para justificar o uso da terra.

\section{Os jovens, o cultivo do fumo e a reprodução social}

Em todas as famílias entrevistadas a procura de atividades não-agrícolas pelos jovens se deu quando os pais plantavam fumo. Em algumas dessas famílias os pais afirmaram que seus filhos "não gostam de trabalhar na terra", independentemente do tipo de cultivo. De fato, em duas delas, os pais ofereceram outro tipo de trabalho agrícola (diferente do fumo) aos filhos e necessitariam de sua mão-de-obra. Mas, mesmo assim, os filhos se negam a herdar o trabalho da terra. Nessas famílias poderíamos dizer que os valores camponeses estão em crise. Ao contrariar a tradição, os filhos não são bem avaliados pelos pais. Por outro lado, alguns dos pais questionam as dificuldades concretas de que os filhos continuem na agricultura, sobretudo os direitos trabalhistas. Diante das suas próprias condições de aposentadoria e das dificuldades por eles referidas de conseguirem "se encostar", ou seja, obter auxílio financeiro da Previdência Social em caso de doença - garantia para que a unidade produtiva e mesmo o sustento imediato da família continuasse viável -, hesitam em recomendar que os filhos permaneçam na agricultura, mesmo que necessitem de sua mão-de-obra.

Outros entrevistados, entretanto, criticam a atitude dos filhos de não trabalharem mais na terra, de aceitarem a condição de assalariados e não se preocuparem com a produção de seu próprio alimento e de, renegando a herança do trabalho na terra, desvalorizarem o trabalho da família. Para estes pais, a terra não é apenas terra, é o resultado do trabalho do pai. É patrimônio da família. Os pais questionam a perda da autonomia da colônia no que diz respeito, sobretudo, à produção de seu próprio alimento. Nessas famílias, pudemos perceber que a colônia, nos dizeres de Woortmann (1990: p.22) "teve a tradição abalada".

Coincidência ou não, a maioria dos casos de filhos que se negam a herdar o trabalho da terra são de famílias que residem em localidades próximas à sede do município. O contato com valores modernos pode ser a causa do questionamento dos valores camponeses. "É como se, no movimento constante de reintegração a uma sociedade global em transformação, o filho realizasse uma 'descoberta do outro', de uma alteridade não-tradicional de novos valores, estabelecendo, com isso, o estranhamento de seu próprio universo e sua desnaturalização (WOORTMANN, 1990: p.56). 


\section{HUMANAS}

Embora, em nosso estudo, nas localidades localizadas mais próximas da sede municipal tenha sido mais comum os pais afirmarem que os filhos não gostam "do serviço da roça", estes mesmos pais afirmaram que seus filhos gostam de residir no espaço rural e, de fato, permanecem morando junto com os pais. Por outro lado, residir na propriedade dos pais é também uma necessidade concreta. Quase todos os pais cujos filhos negam o trabalho da roça disseram com orgulho que o filho, de certa maneira, ainda depende dos pais. Na maioria dos casos os pais fornecem alimentação, moradia, e a roupa lavada. Então, se por um lado a continuidade da unidade produtiva é duvidosa porque a tradição é negada pelos filhos, por outro, é a agricultura mantida com todos os valores do colono evocados pelos pais que possibilita aos jovens iniciar outra profissão. Este fato também foi registrado por Schneider (2003b: p.220), quando verificou que na maioria dos casos de colonos pluriativos nas localidades de Braço do Sul (Blumenau/SC) e de Padre Eterno Ilges (Santa Maria do Herval/RS), pequena parte do salário era destinada às despesas com alimentos. Em nosso estudo de caso, os jovens das localidades mais próximas da sede tem mais facilidade de conseguir emprego porque estão mais próximas das fábricas e, muitas vezes, a própria fábrica disponibiliza o transporte dos operários.

Nestes termos, contudo, quando a atividade não-agrícola é exercida pelos filhos, ela não necessariamente significa um rompimento com a tradição. Afinal, como afirmou Seyferth $(1985,1992)$, a reprodução integral da unidade familiar de produção original na condição de colono é idealizada porque o lote padrão de 25 ha, recebido na época da colonização, nunca seria suficiente para permitir que todos os filhos continuassem na agricultura e, em algum momento do ciclo doméstico, a família não poderia prescindir da proletarização.

Se para alguns jovens negar o cultivo do fumo foi também negar a terra, outros afirmam que gostariam de permanecer na terra, mas se negam a cultivar fumo. Muitas vezes valorizam a possibilidade de receber mensalmente seu salário, o que não era possível, na sua família, com o referido cultivo. Haygert \& Dickie (2004) registraram esse desejo de autonomia financeira manifestados por jovens de diversas localidades do estado de Santa Catarina. As autoras afirmam que "a autonomia monetária é vista por eles como um sinal de maioridade, mesmo estando na casa do pai, não tendo casado, não tendo filhos. Tradicionalmente, a saída da casa do pai ou o casamento era a única forma de adquirir esta autonomia" (op.cit.: p.127).

Esse pode ser mais um questionamento da tradição realizado pelos jovens. Woortmann (1990) afirma que a realização monetária, resultado do trabalho, faz parte da autonomia do camponês. Os jovens podem estar questionando os modos tradicionais para obtenção dessa autonomia. No entanto, registramos alguns casos de famílias monoativas em que os jovens, cultivando fumo junto com sua família, 
tinham autonomia financeira - pois a renda era dividida em partes iguais entre os membros da família que se dedicavam ao cultivo - mas não desejavam continuar plantando fumo e estavam quase decididos a abandonar a atividade agrícola. Invariavelmente os jovens afirmaram, assim como muitos dos pais, que o trabalho do fumo é um trabalho muito penoso. Paulilo (1990: p.154) ao estudar a fumicultura em algumas localidades de Santa Catarina afirmou que "a auto-exploração da família é uma das características principais da fumicultura. Aceitação de um trabalho tão penoso só é justificada, pelos entrevistados, em função do rendimento do produto. Também é a atividade que melhor permite o trabalho feminino, infantil e mesmo o de pessoas idosas, quando chega a fase da classificação".

As famílias pluriativas cujos jovens abandonaram a atividade agrícola quando os pais plantavam fumo são famílias que estavam quase na mesma fase do ciclo doméstico de várias famílias monoativas que entrevistamos: alguns dos filhos já chegaram ou estão se aproximando da idade em que podem trabalhar legalmente. A procura pelo emprego sempre se deu quando se cultivava fumo na casa paterna. O fumo não é uma cultura trabalhada com satisfação. As famílias entrevistadas não falavam com orgulho do produto de seu trabalho. Ao contrário, o fumo é tratado com desprezo pelos agricultores.

A maioria dos jovens entrevistados que eram fumicultores desejavam abandonar a atividade. Cada um deles apresentava uma razão particular, uma necessidade concreta que o levava a pensar em abandonar o cultivo do fumo, mas não econômica (problemas de saúde, mal estar durante a colheita, etc.). Assim todos os agricultores reclamam do trabalho árduo exigido pela cultura do fumo e às vezes questionam o pequeno retorno econômico. Mas esta não é a maioria dos casos. Existem situações em que os agricultores, inclusive os jovens que pretendiam deixar o fumo, afirmaram que o cultivo do fumo dava mais retorno econômico do que um emprego na fábrica - considerada por eles a única alternativa ao cultivo do fumo.

Quando os filhos não se negam a herdar o trabalho da terra, quando a família dispõe de possibilidades concretas, executam-se diferentes arranjos intrafamiliares para que a unidade produtiva e a vida no espaço rural possam se perpetuar. Sobre este aspecto, já mencionamos o caso da família em que os pais não abandonam o cultivo do fumo para ajudar o filho, e do irmão que voltou da cidade para ajudar na roça. Por outras vezes, parecem estar em jogo normas que contrariam a moral camponesa - o filho assalariar o pai ou a família transformar-se numa empresa - mas são estratégias para, numa lógica familiar, permitir que o filho continue "colono".

Sobretudo nas localidades mais distantes existe ainda um outro fator que estimula os jovens a procurarem empregos na cidade - o vazio social. 
$\mathrm{O}$ vazio social parece também estar relacionado ao cultivo do fumo. A falta de motivação relacionada ao plantio do fumo teria feito com que muitos jovens das localidades mais distantes fossem morar na cidade porque não poderiam permanecer com empregos urbanos e residir no estabelecimento rural. Isso gerou um vazio social nas localidades mais distantes. Sobretudo para os jovens que não constituíram família, esse isolamento constitui-se numa dificuldade concreta: está em jogo a possibilidade de reprodução social.

Tô aborrecido de trabalhar no fumo. Da juventu-
de não tem mais ninguém quase. [...] Então a gente
tem que pensar em ir embora também. Se a gente
querer olhar, o fumo dá quase mais [dinheiro]
que na cidade. [...] Então tem que procurar ativida-
de de lazer, né? [...] Aqui elas (moças) pegam e vão
tudo embora. Aí os rapazes solteiros, pegam e vão
embora também. A maioria é isso mesmo... [...] Não
é por causa do fumo não...
(Agricultor solteiro, 24 anos, Localidade Areia Alta).

Vale destacar que Carneiro (1999: p.104-106) ao entrevistar jovens rurais, dos municípios de São Pedro da Serra (RJ) e Nova Pádua (RS), registrou entre eles o gosto pela vida no espaço rural, devido ao apego à família, à comunidade, e à tranqüilidade. Por outro lado, também registrou um descontentamento dos jovens em relação à falta de recursos (educação e comércio), à falta de lazer, à distância da cidade, falta de opções de trabalho qualificado, à penosidade do trabalho na roça, etc. Em nosso estudo, nas localidades mais próximas da sede municipal como nos Lageados Alto e Baixo pudemos perceber, pelo relato dos agricultores, uma vida social mais intensa, mais reuniões entre parentes e vizinhos e um lugar para encontro dos jovens. Conforme informante local, os jovens procuram emprego urbano para poder deixar de plantar fumo, mas permanecem morando na comunidade.

\section{Considerações finais}

É difícil apresentarmos de maneira isolada a influência de uma ou outra categoria simbólica identificadora do colono, na tomada de decisão, porque os agricultores entrevistados implicitamente estabeleciam relações entre as categorias que lhes conferem sua identidade social, corroborando com o que afirmava Woortmann (1990). Ou seja, que ao falar do trabalho, o agricultor fala da família e da terra - estas, categorias nucleantes e relacionadas. Embora os motivos que levam o estabelecimento produtivo a ficar com a mão-de-obra reduzida variem, as categorias da campesinidade e do colono estão presentes entre as justificativas e sempre de maneira relacional. 
Tendo em vista a importância do cultivo do fumo para as famílias entrevistadas, cabe salientar que, a despeito das diferenças entre as dificuldades concretas apresentadas, todos os colonos nos relataram que, quando começam a colher o fumo, não podem parar até que a estufa esteja cheia. Independentemente das condições climáticas, com chuva ou sol, o fumo deve ser colhido. São destas condições que todos os colonos reclamaram. Assim, acreditamos que além da questão econômica ou, no âmbito cultural, além do questionamento sobre a autonomia financeira, especialmente os jovens colocam em questão o trabalho árduo, tanto como os problemas de saúde e o vazio social - dificuldades concretas, mas não necessariamente econômicas. Além disso, ao mesmo tempo em que os agricultores prezavam sua liberdade de não cumprir horário, reclamavam que no cultivo do fumo não se pode olhar o tempo, nem a chuva, nem o sol. Mesmo sem o patrão, o "fumo obriga a trabalhar". É a perda da liberdade de poder estabelecer o próprio ritmo de trabalho, que contribui ainda mais para que o trabalho se torne penoso e doentio.

Poderíamos dizer também que, nos locais onde o fumo é a "única alternativa" e onde não é possível deslocar-se diariamente para as fábricas, um importante fator a impulsionar os jovens a saírem da agricultura é a carência de vida sócio-cultural.

A predominância da lavoura temporária e a pequena propriedade da terra verificadas em Botuverá são características que vão além de uma mera descrição física da paisagem, estando enraizadas nos traços culturais da população em questão. A propriedade da terra e a possibilidade de torná-la produtiva para a "família" com base no seu próprio trabalho são tidas, pelos agricultores, como condição essencial ao seu modo de vida. Da mesma forma, a diversidade de produtos cultivados está associada à importância dada por eles à produção de seu próprio alimento, do que resulta que esses agricultores são, em geral, policultores e criadores de pequenos animais. E, é a produção para consumo familiar que muitas vezes possibilita, contraditoriamente, o abandono da atividade agrícola pelos jovens, já que estes muitas vezes dependem dos alimentos produzidos na "colônia".

\section{Referências bibliográficas}

ALMEIDA, M. W. B. Redescobrindo a família rural. Revista Brasileira de Ciências Sociais. v.1, n. 1, p.66-82, jun. 1986.

CARNEIRO, M.J. O ideal rurbano: campo e cidade no imaginário dos jovens rurais. In: TEIXEIRA DA SILVA, F.C; SANTOS,R. \& COSTA, L.F.C. Mundo Rural e Politica. Ensaios interdisciplinares. Rio de Janeiro: Campus,1999. 
ECKERT, N. A. Estratégia de desenvolvimento rural: o caso da fumicultura como agente de desenvolvimento rural de pequenas unidades agrícolas em Botuverá, SC, Brasil. 1985. 355f. Dissertatio ad Doctoratum in Facultate Scientiarum Socialium - Facoltà di Scienze Sociali, Pontificae Universitas Gregorianae, Roma.

HAYGERT. M. L. \& DICKIE, M. A. Produzindo Vida: jovens rurais, ethos camponês e agroecologia. In: AUED, B. W. \& PAULILO, M. I. S. Agricultura familiar. Florianópolis: Insular, 2004. p.109-132.

IBGE (2004a). BOTUVERÁ. Disponível em <http://www.ibge.gov.br/cidadesat/default.php>, acessado em maio de 2004.

IBGE, 2004b. Censo agropecuário 1995-1996. Tabela 11.(Dados obtidos com auxílio de funcionário da biblioteca do IBGE em Florianópolis/SC, em consulta pessoal realizada em maio de 2004).

IBGE, 2004c. Sistema IBGE de recuperação automática (SIDRA), Tabela 1612 (fonte: Produção Agrícola Municipal 2002), disponível em www.ibge.gov.br, acessado em 22.07.04.

IBGE, 2004d. Sistema IBGE de recuperação automática (SIDRA), Tabela 1613 (fonte: Produção Agrícola Municipal 2002), disponível em www.ibge.gov.br, acessado em 26.07.04.

PAULILO, M. I. S. Produtor e agroindústria: consensos e dissensos - o caso de Santa Catarina. Florianópolis: Editora da UFSC, 1990. 182p.

SCHNEIDER, S. Teoria social, agricultura familiar e pluriatividade. Revista Brasileira de Ciências Sociais. v. 18, n. 51, p.99-121, fev. 2003a.

SCHNEIDER, S. A pluriatividade na agricultura familiar. Porto Alegre: Editora da UFRGS, 2003b.254p.

SEYFERTH, G. Identidade camponesa e identidade étnica (um estudo de caso). In: Anuário Antropológico/91. Rio de Janeiro: Tempo Brasileiro, 1993. p.31-63.

SEYFERTH, G. Herança e estrutura familiar camponesa. Boletim do Museu Nacional. Rio de Janeiro, n.52, p.1-27, 1985.

SEYFERTH, G. Camponeses ou operários? O significado da categoria colono numa situação de mudança. Revista do Museu Paulista. São Paulo, vol. 29, p.73-96, 1984.

WOORTMANN, K. Com parente não se neguceia. O campesinato como ordem moral. In: Anuário Antropológico/87. Rio de Janeiro: Tempo Brasileiro, 1990. 